\title{
Heat Resistant Polymer-Grafted Carbon Black. Grafting of Poly-2-oxazolidones onto Carbon Black during the Polyaddition of Diepoxides with Diisocyanates
}

\author{
Norio TsuboKawA, Toshiaki KoH’E Marcia Michiko KumashitA, \\ and Yasuo SONE
}

\begin{abstract}
Department of Applied Chemistry, Faculty of Engineering, Niigata University, Ikarashi 2-8050, Niigata 950-21, Japan
\end{abstract}

(Received September 24, 1985)

\begin{abstract}
The polyadditions of diepoxides with diisocyanates were carried out by use of carbon black having OLi groups, which was introduced by the reaction of oxygen containing groups on carbon black with $n$-butyllithium $(\mathrm{BuLi})$, as initiator. During the polymerization, poly-2oxazolidone or polyoxazolidone-isocyanurate formed was grafted onto the carbon black surface depending upon polymerization conditions. The following conditions were most suitable for the preparation of poly-2-oxazolidone-grafted carbon black with a high grafting ratio: (1) the addition of diisocyanate to a mixture of diepoxide and initiator (CB-OLi) in the absence of free BuLi, (2) a polymerization temperature of $180^{\circ} \mathrm{C}$ or higher. The grafting ratio of poly-2-oxazolidone was determined to be $50-200 \%$; for instance, the grafting ratio of poly-2-oxazolidone from 2,2-bis $[p$ (2,3-epoxypropoxy)phenyl]propane and tolylene 2,4-diisocyanate increased with an increase in conversion up to $170 \%$. The carbon black obtained gave a stable colloidal dispersion in $N, N$ dimethylformamide. The thermogravimetric analysis indicated that poly-2-oxazolidone-grafted carbon black was stable in air up to $300^{\circ} \mathrm{C}$.

KEY WORDS Carbon Black / Grafting onto Carbon Black / Poly-2oxazolidone / Polyoxazolidone-Isocyanurate / Heat Resistant Polymer / Lithium Phenolate Group on Carbon Black / Polyaddition / Diepoxide / Diisocyanate /
\end{abstract}

In order to provide a better understanding of carbon black which can be dispersed easily in polymers and organic solvents, the grafting of various kinds of polymers has been widely investigated. $^{1,2}$ For instance, it has been reported that during the polymerization of vinyl monomers in the presence of carbon black using radical, ${ }^{3}$ anionic, ${ }^{4}$ and cationic ${ }^{5}$ initiators, a part of a polymer formed was grafted onto the carbon black surface. We have reported anionic grafting from alkali metal carboxylate (COOM) group, ${ }^{6,7}$ cationic grafting from benzoyl perchlorate $\left(\mathrm{COClO}_{4}\right)$ group, ${ }^{8-10}$ and radical grafting from hydroxymethyl $\left(\mathrm{CH}_{2} \mathrm{OH}\right)$ group on carbon black. ${ }^{11}$

However, grafting onto or from carbon black has been confined to the system of addition polymerization (chain reaction) and so far, the surface grafting in the system of polyaddition and polycondensation has not been reported. Therefore, in this paper, the grafting of a heat resistant polymer onto carbon black in the system of polyaddition is investigated.

In general, poly-2-oxazolidone, a well known heat resistant polymer, was synthesized from a diepoxide and a diisocyanate by use of quaternary ammonium halides, ${ }^{12,13}$ lithium chloride, ${ }^{14}$ and lithium $n$-butoxide ${ }^{15}$ as catalyst. The polymer was stable in air up to $300^{\circ} \mathrm{C}$ and soluble in organic solvents such as $\mathrm{N}, \mathrm{N}$-dimethylformamide. 
This paper deals with the preparation of poly-2-oxazolidone-grafted carbon black during the polyaddition of a diepoxide with a diisocyanate using OLi groups on carbon black as initiator. In addition, the thermal stability of the poly-2-oxazolidone-grafted carbon black was studied.

\section{EXPERIMENTAL}

\section{Materials}

The carbon black used was channel black Neospectra II $\left(906 \mathrm{~m}^{2} \mathrm{~g}^{-1}\right.$, Columbian Carbon Co., U.S.A.). The content of the quinonic oxygen, carboxyl, and phenolic hydroxyl groups of the carbon black was $0.92,0.40$, and 0.24 meq $^{-1}$, respectively. The carbon black was dried in vacuo at $110^{\circ} \mathrm{C}$ before use.

The diglycidyl ether of Bisphenol-A (DGBA), 2,2-bis[ $p$-(2,3-epoxypropoxy)phenyl]propane, obtained from Dow Chemical Co., U.S.A. under the designation DER-332, was dried in vacuo at $40^{\circ} \mathrm{C}$ before use. 1,4-Bis(2,3-epoxypropoxy)butane (EPB) and 1,6-bis(2,3-epoxypropoxy)hexane (EPH) were of reagent grade (Aldrich Chemical Co., U.S.A.) and distilled under reduced pressure.

Tolylene 2,4-diisocyanate (TDI), 4,4'-diphenylmethane diisocyanate (MDI), and 1,6hexamethylene diisocyanate (HMDI) were also of reagent grade (Tokyo Kasei Kogyo Co., Ltd., Japan) and purified by distillation under reduced pressure.

n-Butyllithium (BuLi), about 15\% hexane solution, obtained from Wako Pure Chemical Ind. Ltd., Japan, was used without further purification. The content of $\mathrm{BuLi}$ was determined by titration before use. ${ }^{16}$

$o$-Dichlorobenzene, $\quad \mathrm{N}, \mathrm{N}$-dimethylformamide (DMF), and methylene chloride were also purified by the usual methods.
Pretreatment (Introduction of OLi Group onto Carbon Black) and Polymerization Procedure

Into a $100 \mathrm{ml}$ teardrop-type flask that contained $0.30 \mathrm{~g}$ of carbon black and $5.0 \mathrm{ml}$ of $o$ dichlorobenzene, $0.40 \mathrm{mmol}$ of BuLi (hexane solution) was added under dry nitrogen. The mixture was stirred with a magnetic stirrer at room temperature for $1 \mathrm{~h}$. Subsequently, $10.0 \mathrm{ml}$ of $o$-dichlorobenzene solution of a diepoxide $\left(0.20 \mathrm{moll}^{-1}\right)$ was added to the mixture with stirring at $180^{\circ} \mathrm{C}$. After $1 \mathrm{~h}, 10.0 \mathrm{ml}$ of $o$-dichlorobenzene solution of a diisocyanate $\left(0.20 \mathrm{moll}^{-1}\right)$ was added under nitrogen and the polymerization was conducted at $180^{\circ} \mathrm{C}$. After a definite time, the contents of the flask were poured into a large amount of methanol to precipitate the polymer and polymergrafted carbon black. The precipitate was filtered, washed with methanol, and dried in vacuo at $40^{\circ} \mathrm{C}$. The conversion was calculated by the following equation:

Conversion $(\%)$

$$
=\frac{\text { Precipitate }(\mathrm{g})-\text { Carbon black }(\mathrm{g})}{\text { Diepoxide }(\mathrm{g})+\text { Diisocyanate }(\mathrm{g})} \times 100
$$

\section{Determination of Grafting Ratio}

To separate the ungrafted polymer from the reaction product which contains the carbon black, the product was dispersed in DMF at $80^{\circ} \mathrm{C}$ and extracted with DMF and methylene chloride using a Soxhlet apparatus until no more polymer could be detected in the reflux- 
ing solvent. The grafting ratio was determined by the following equation:

Grafting ratio $(\%)$

$$
=\frac{\text { Polymer grafted }(\mathrm{g})}{\text { Carbon black used }(\mathrm{g})} \times 100
$$

\section{RESULTS AND DISCUSSION}

\section{Introduction of OLi Groups onto Carbon Black}

\section{(Pretreatment)}

It has been reported that oxygen containing groups, that is, quinonic oxygen, carboxyl, and phenolic hydroxyl groups, on the carbon black surface react with BuLi to give OLi groups. ${ }^{17}$ Ohkita et al. reported the anionic grafting

$$
\begin{aligned}
& \mathrm{CB}-\mathrm{OH}+\mathrm{BuLi} \rightarrow \mathrm{CB}-\mathrm{OLi}+\mathrm{BuH} \\
& \mathrm{CB}>\mathrm{C}=\mathrm{O}+\mathrm{BuLi} \rightarrow \mathrm{CB}>\mathrm{C}-\mathrm{OLi} \\
& \mathrm{Bu} \\
& \mathrm{CB}-\mathrm{COOH}+\mathrm{BuLi} \rightarrow \underset{\mathrm{O}}{\mathrm{CB}-\mathrm{C}-\mathrm{OLi}}+\mathrm{BuH}
\end{aligned}
$$

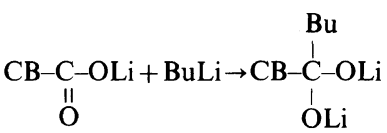

of methyl methacrylate and acrylonitrile using OLi groups on carbon black as initiator. ${ }^{18}$ Furthermore, we found that OLi groups on carbon black are able to initiate the hydrogen transfer polymerization of acrylamide to give poly- $\beta$-alanine (Nylon 3 )-grafted carbon black. ${ }^{19}$

Dileone has reported the synthesis of high molecular weight poly-2-oxazolidone, soluble in DMF, from a diepoxide and a diisocyanate using lithium $n$-butoxide as catalyst. ${ }^{15}$ Therefore, the polyaddition of a diepoxide with a diisocyanate using OLi groups on carbon black as initiator was carried out and the grafting of poly-2-oxazolidone onto carbon black was examined.

In order to find the proper conditions of pretreatment for the introduction of $\mathrm{OLi}$ groups onto carbon black, by use of $0.30 \mathrm{~g}$ of Neospectra II pretreated with various amounts of BuLi, the polyaddition of DGBA with TDI

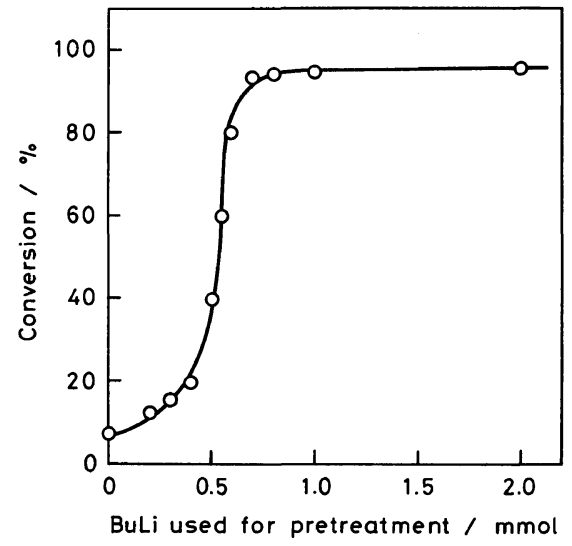

Figure 1. Effects of the amount of BuLi on the pretreatment of Neospectra II $(0.30 \mathrm{~g})$. Pretreatment: Neospectra II, $0.30 \mathrm{~g}$; $o$-dichlorobenzene, $5.0 \mathrm{ml}$; room temp.; $1 \mathrm{~h}$. Polymerization: DGBA $\left(0.20 \mathrm{moll}^{-1}\right)$, $10.0 \mathrm{ml}$; TDI $\left(0.20 \mathrm{moll}^{-1}\right), 10.0 \mathrm{ml} ; 180^{\circ} \mathrm{C} ; 30 \mathrm{~min}$ (TDI was added after the addition of DGBA).

was carried out at $180^{\circ} \mathrm{C}$. In such a polyaddition of a diepoxide with a diisocyanate, the order of monomer addition was a very important factor. ${ }^{15}$ In this experiment, a diepoxide was added to the initiator (CB-OLi) at $180^{\circ} \mathrm{C}$ and then after $1 \mathrm{~h}$, the polymerization was initiated by the addition of a diisocyanate to the mixture.

The results are shown in Figure 1. The amount of the oxygen containing group on $0.30 \mathrm{~g}$ of Neospectra II is almost equivalent to $0.56 \mathrm{mmol}$ of BuLi. ${ }^{19}$ Accordingly, above the equivalent point, the polymerization is initiated by $\mathrm{OLi}$ groups and free BuLi. But below the equivalent point, the polymerization is initiated by $\mathrm{OLi}$ groups only, because $\mathrm{BuLi}$ is consumed by oxygen containing groups on carbon black during the pretreatment.

Figure 1 shows that the rate of the polymerization increases with an increase in the $\mathrm{OLi}$ group content of carbon black up to the equivalent point. However, it was found that in the presence of free $\mathrm{BuLi}$, the rate of the polymerization was extremely high and the conversion after $30 \mathrm{~min}$ went up to about $90 \%$. 
Polyaddition of DGBA with TDI Initiated by $\mathrm{CB}-\mathrm{OLi}$ and the Structure of Polymers Formed

The polyaddition of DGBA with TDI was carried out by use of Neospectra II pretreated with $0.2,0.3,0.4$, and $0.8 \mathrm{mmol}$ of BuLi. As mentioned above, in the system of Neospectra II pretreated with $0.8 \mathrm{mmol}$ of $\mathrm{BuLi}$, the polyaddition is initiated by $\mathrm{OLi}$ groups and free BuLi.

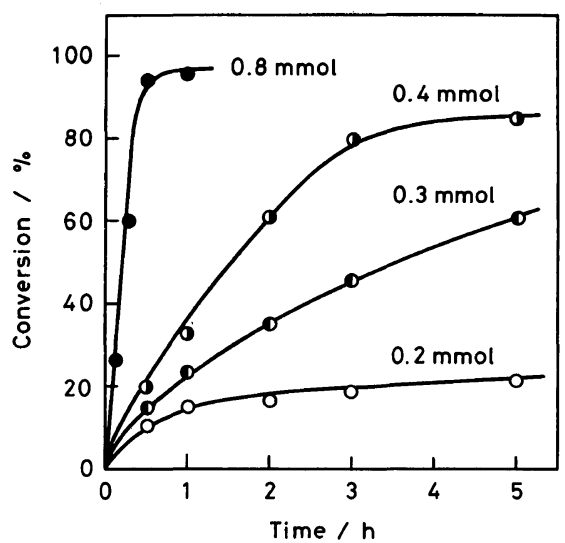

Figure 2. Polyaddition of DGBA with TDI catalyzed by Neospectra II pretreated with various amounts of BuLi. Pretreatment: Neospectra II, 0.30 g; BuLi, 0.2, 0.3, 0.4 , and $0.8 \mathrm{mmol}$; $o$-dichlorobenzene, $5.0 \mathrm{ml}$; room temp, $1 \mathrm{~h}$. Polymerization: DGBA $\left(0.20 \mathrm{moll}^{-1}\right)$, $10.0 \mathrm{ml}$; TDI $\left(0.20 \mathrm{moll}^{-1}\right), 10.0 \mathrm{ml} ; 180^{\circ} \mathrm{C}$ (TDI was added after the addition of DGBA).
The results are shown in Figure 2. Figure 2 clearly shows that the polyaddition of DGBA with TDI is initiated by OLi groups on carbon black, but the polymerization using Neospectra II pretreated with $\mathrm{BuLi}$ less than 0.2 mmol is considerably slow.

From the reaction product, the ungrafted polymer was isolated by Soxhlet extraction with DMF and methylene chloride. The infrared spectra of the ungrafted polymers obtained from the above polymerization are shown in Figure 3.

The infrared spectra of the polymers obtained from the polyaddition using Neospectra II pretreated with $0.2,0.3$, and $0.4 \mathrm{mmol}$ of $\mathrm{BuLi}$, namely in the absence of free $\mathrm{BuLi}$, exhibited a strong absorption at $1750 \mathrm{~cm}^{-1}$. This absorption is characteristic of the carbonyl group of an oxazolidone ring. ${ }^{13,14,20}$ The infrared spectra were identical with that of poly-2-oxazolidone prepared by the method of Dileone. ${ }^{15}$ However, the infrared spectra of the ungrafted polymers obtained from the reaction using excess $\mathrm{BuLi}(0.8 \mathrm{mmol})$ for the pretreatment, exhibited a strong absorption at $1710 \mathrm{~cm}^{-1}$ besides the one at $1750 \mathrm{~cm}^{-1}$. This absorption at $1710 \mathrm{~cm}^{-1}$ is characteristic of the carbonyl group of an isocyanurate ring. ${ }^{21}$ This indicates that polyoxazolidone-isocyanurate is

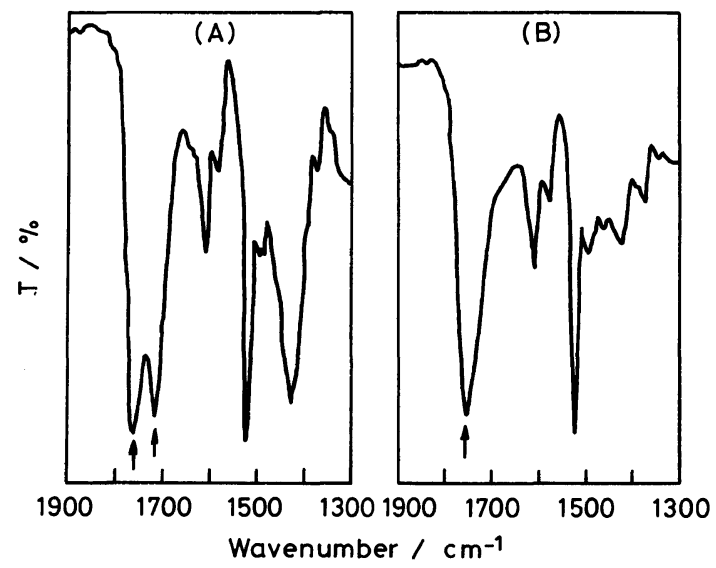

Figure 3. Infrared spectra of ungrafted polymers obtained from the polyaddition of DGBA with TDI. Polymerization conditions are given in Figure 2. The amounts of BuLi used for the pretreatment: (A), $0.8 \mathrm{mmol}$; (B), $0.2,0.3$, and $0.4 \mathrm{mmol}$. 
formed when the polyaddition is carried out in the presence of free BuLi.<smiles>[R]OC[C@H]1CN([R1])C(=O)N([R1])C(=O)N([R1])C1=O</smiles>

Based on these results, it is concluded that in order to obtain poly-2-oxazolidone-grafted carbon black, the polymerization should be carried out in the absence of free BuLi.

The intrinsic viscosity of these polymers in $\mathrm{DMF}$ at $30.0^{\circ} \mathrm{C}$ was determined to be 0.20 $0.32 \mathrm{dlg}^{-1}$.

\section{Effects of the Order of Monomer Addition on the Polyaddition}

The structure of a polymer formed by the polyaddition was found to be affected by the order of monomer addition. For instance, when a diepoxide and a diisocyanate were added to CB-OLi at the same time or a diisocyanate was added to the initiator before the addition of a diepoxide, the predominant product was polyisocyanurate, which was characterized by the infrared spectra shown in Figure 4.

Accordingly, it became apparent that the most suitable conditions for the grafting of poly-2-oxazolidone onto carbon black involve the addition of a diisocyanate to a mixture of a diepoxide and the initiator (CB-OLi).

\section{Effects of Temperature on the Polyaddition}

The effects of temperature on the polyaddition of DGBA with TDI were examined by use of Neospectra II $(0.30 \mathrm{~g})$ pretreated with $0.4 \mathrm{mmol}$ of $\mathrm{BuLi}$ as catalyst. In the system, the polymerization was catalyzed by $\mathrm{OLi}$ groups only. The results are shown in Figure 5. Figure 5 shows that the rate of the polyaddition increases with a rise in the reaction temperature.

The infrared spectra of the ungrafted polymers obtained from the above polymeriza-

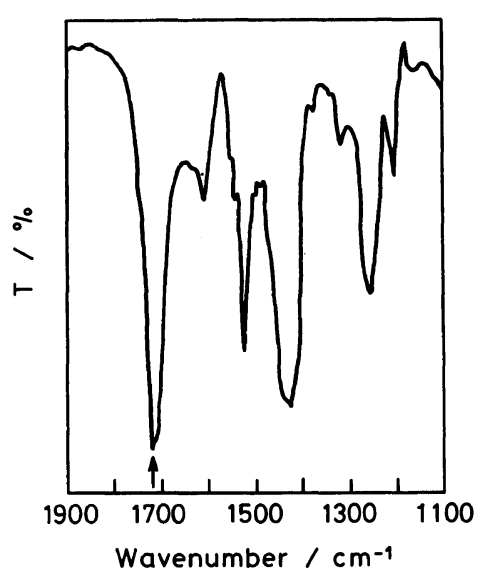

Figure 4. Infrared spectrum of the ungrafted polymer obtained from the polyaddition of DGBA with TDI. Polymerization conditions are the same as those shown in Figure $2(0.4 \mathrm{mmol}$ of BuLi was used for the pretreatment), but monomers were added to CB-OLi at the same time.

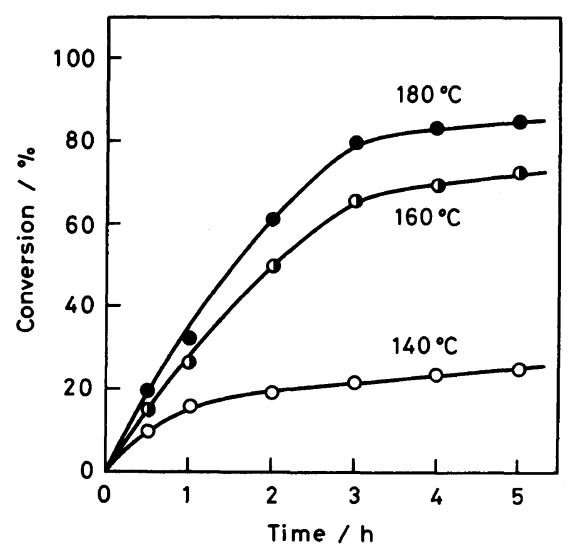

Figure 5. Effects of temperature on the polyaddition of DGBA with TDI. Pretreatment: Neospectra II, $0.30 \mathrm{~g}$; BuLi, $0.4 \mathrm{mmol}$; $o$-dichlorobenzene, $5.0 \mathrm{ml}$; room temp, $1 \mathrm{~h}$. Polymerization: DGBA $\left(0.20 \mathrm{moll}^{-1}\right), 10.0 \mathrm{ml}$; TDI $\left(0.20 \mathrm{moll}^{-1}\right), 10.0 \mathrm{ml}$ (TDI was added after the addition of DGBA). 


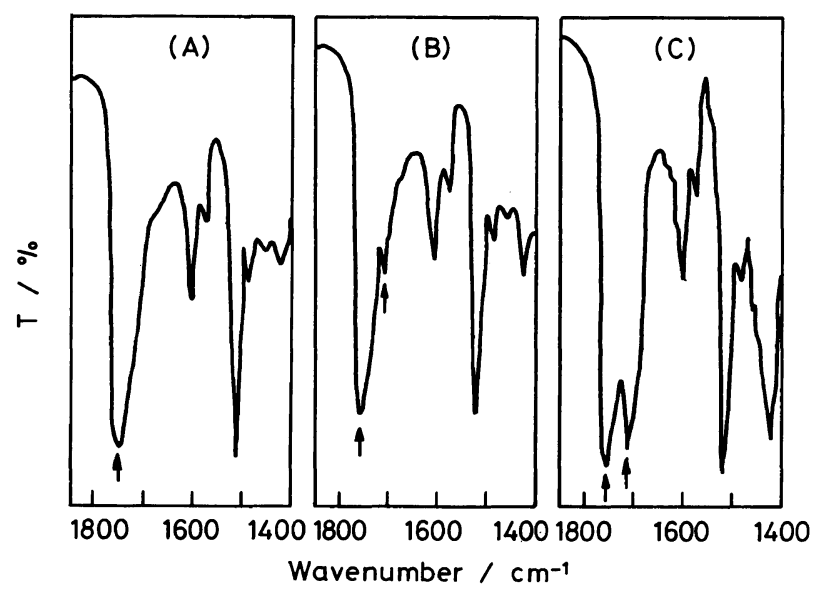

Figure 6. Infrared spectra of ungrafted polymers obtained from the polyaddition of DGBA with TDI. Polymerization conditions are given in Figure 5. Polymerization temperature: $(\mathrm{A}), 180^{\circ} \mathrm{C} ;(\mathrm{B}), 160^{\circ} \mathrm{C} ;(\mathrm{C})$, $140^{\circ} \mathrm{C}$.

tion are shown in Figure 6. The infrared spectrum of the polymer obtained at $180^{\circ} \mathrm{C}$ exhibited a strong absorption at $1750 \mathrm{~cm}^{-1}$ (oxazolidone ring), but those obtained at 160 and $140^{\circ} \mathrm{C}$ exhibited an absorption at $1710 \mathrm{~cm}^{-1}$ (isocyanurate ring) besides the one at $1750 \mathrm{~cm}^{-1}$. In addition, the intensity of the absorption at $1710 \mathrm{~cm}^{-1}$ was found to increase by lowering the polymerization temperature from 160 to $140^{\circ} \mathrm{C}$ as shown in Figure 6 . These results indicate that the content of isocyanurate ring in the polymer increases with a lowering of the polymerization temperature.

Based on the above results, it is concluded that when the polymerization is carried out at below $160^{\circ} \mathrm{C}$, polyoxazolidone-isocyanurate is formed even in the absence of free BuLi. Therefore, a polymerization temperature above $180^{\circ} \mathrm{C}$ is required for the preparation of poly-2-oxazolidone-grafted carbon black.

\section{Proof of Grafting onto Carbon Black}

The carbon black obtained from the polymerization gave a stable colloidal dispersion in DMF. For instance, when poly-2-oxazolidone (from DGBA and TDI)-grafted carbon black was dispersed in DMF and the dispersion was allowed to stand at room temperature, the

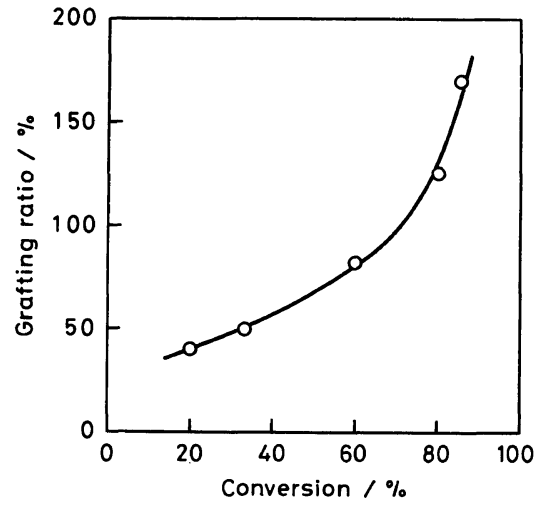

Figure 7. Relationship between the conversion and grafting ratio of poly-2-oxazolidone from DGBA and TDI at $180^{\circ} \mathrm{C}$. Polymerization conditions are given in Figure 5.

carbon black precipitation was scarcely observed after 1 month. This suggests that the polymer is grafted onto carbon black.

To ensure the grafting of the polymer onto carbon black, the grafting ratio was determined. The results are shown in Figure 7.

As shown in Figure 7 , the grafting ratio increased to about $170 \%$ as the conversion increased, indicating that in such a polymerization system, poly-2-oxazolidone is effectively grafted onto carbon black. The grafting onto 
Table I. Grafting of poly-2-oxazolidones onto carbon black ${ }^{\mathrm{a}}$<smiles>[H][R]([H])(C)C1C[C@H](CO[R]OCC(C)(C)C)OC1=O</smiles>

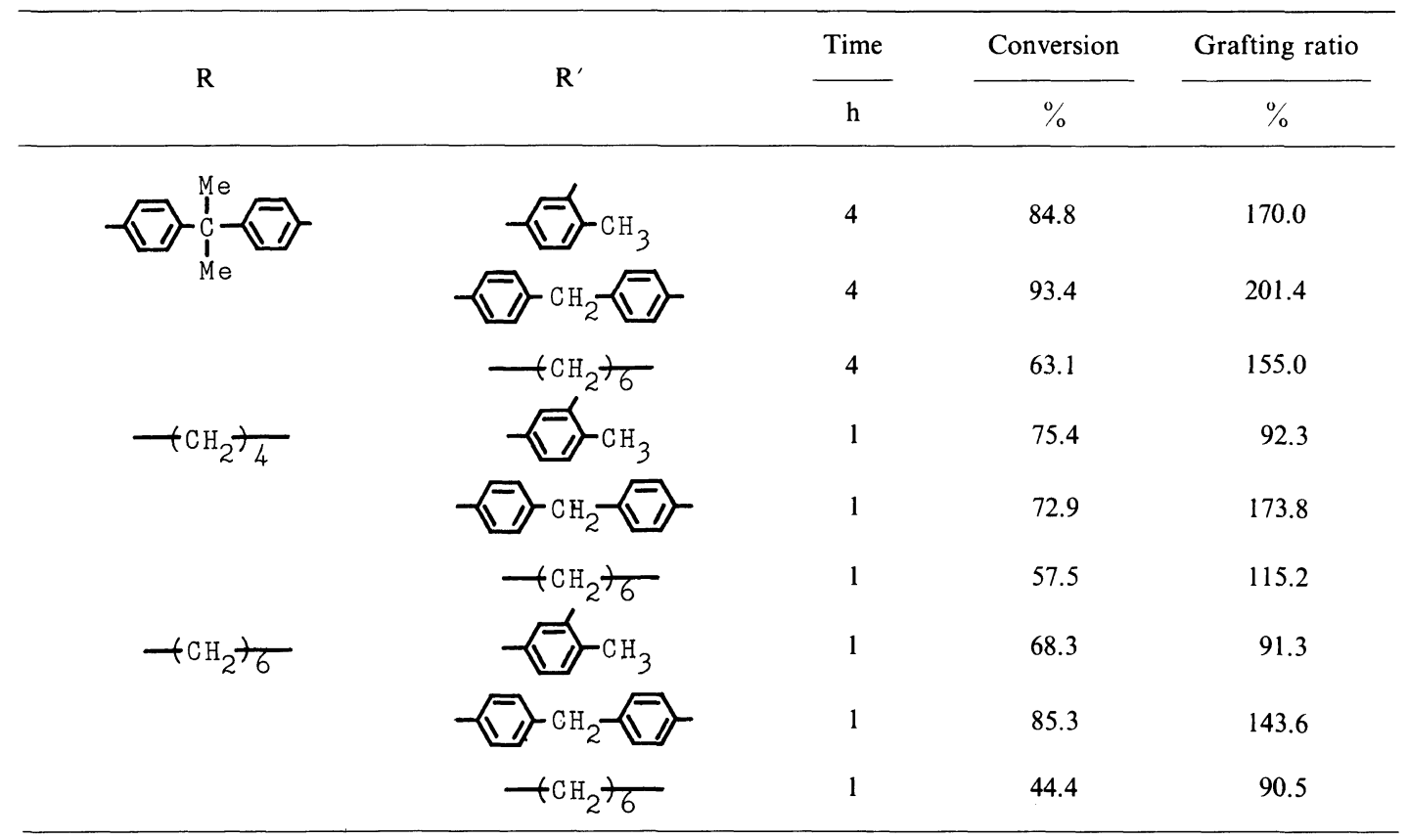

a Polymerization conditions are given in Figure 8.

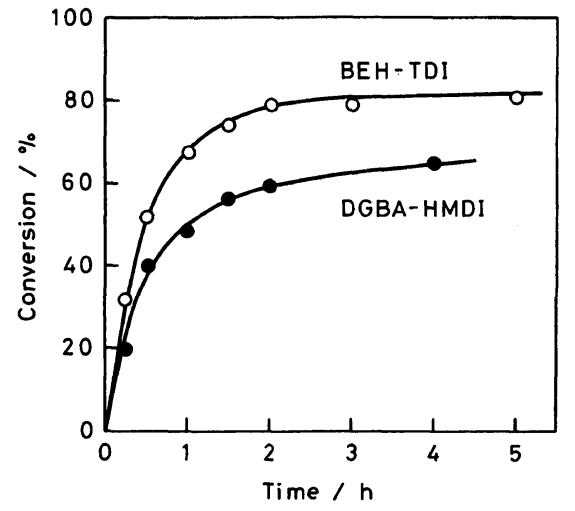

Figure 8. Polyaddition of diepoxide with diisocyanate catalyzed by the OLi group on carbon black. Pretreatment: Neospectra II, $0.30 \mathrm{~g}$; BuLi, $0.4 \mathrm{mmol}$; $o$-dichlorobenzene, $5.0 \mathrm{ml}$; room temp, $1 \mathrm{~h}$. Polymerization: diepoxide $\left(0.20 \mathrm{moll}^{-1}\right), 10.0 \mathrm{ml}$; diisocyanate $\left(0.20 \mathrm{moll}^{-1}\right), 10.0 \mathrm{ml} ; 180^{\circ} \mathrm{C}$ (diisocyanate was added after the addition of diepoxide).

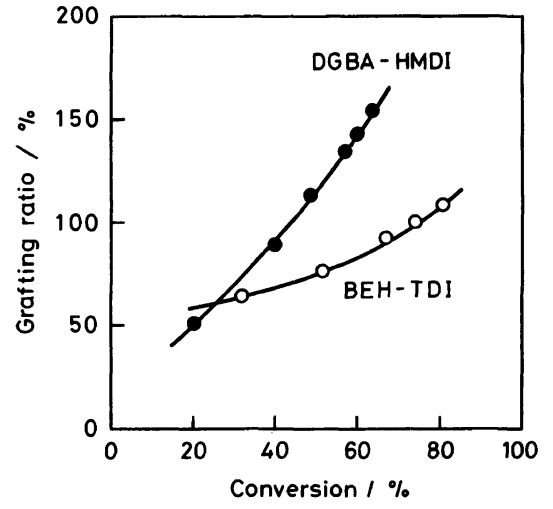

Figure 9. Relationship between the conversion and grafting ratio of poly-2-oxazolidone. Polymerization conditions are given in Figure 8.

carbon black is considered to be based on the reaction of the carbon black surface with the polymer formed. A more detailed grafting mechanism is now under investigation. 
Grafting of Various Kinds of Poly-2-oxazolidones onto Carbon Black

The grafting of poly-2-oxazolidones onto carbon black during the polyaddition of various kinds of diepoxides and diisocyanates using the OLi group on carbon black as initiator was carried out. Figure 8 shows the time-conversion curves of the polyaddition of BEH with TDI and that of DGBA with HMDI. The relationship between the conversion and grafting ratio of these poly-2oxazolidones onto carbon black obtained from the polymerization is shown in Figure 9.

The results of the grafting of various kinds of poly-2-oxazolidones onto carbon black are summarized in Table I. All polymers obtained from the polymerization shown in Table I were identified as the corresponding poly-2-oxazolidone by infrared spectroscopy.

From these results, it is concluded that, during the polyaddition of a diepoxide with a diisocyanate using the OLi group on carbon black as initiator, various kinds of poly-2oxazolidones are effectively grafted onto the carbon black surface.

Thermal Stability of Poly-2-oxazolidone-Grafted Carbon Black

It has been reported that poly-2-oxazolidones are stable in air up to $300^{\circ} \mathrm{C} .{ }^{14}$ Thus, the thermal behavior of poly-2oxazolidone-grafted carbon black was examined by thermogravimetric analysis. Figure 10 shows the thermogravimetric curves of untreated Neospectra II, poly-2-oxazolidonegrafted carbon black, and polyester-grafted carbon black ${ }^{22}$ at $2.5^{\circ} \mathrm{C} \mathrm{min}^{-1}$ in air.

As shown in Figure 10, polyester-grafted carbon black exhibited an initial weight loss at about $200^{\circ} \mathrm{C}$ in air. However, the initial inflection point on the thermogravimetric curve of poly-2-oxazolidone-grafted carbon black occurred at $300^{\circ} \mathrm{C}$. This may be due to the difference in thermal stability between these grafted polymers, because Neospectra II is stable up to $600^{\circ} \mathrm{C}$ in air.

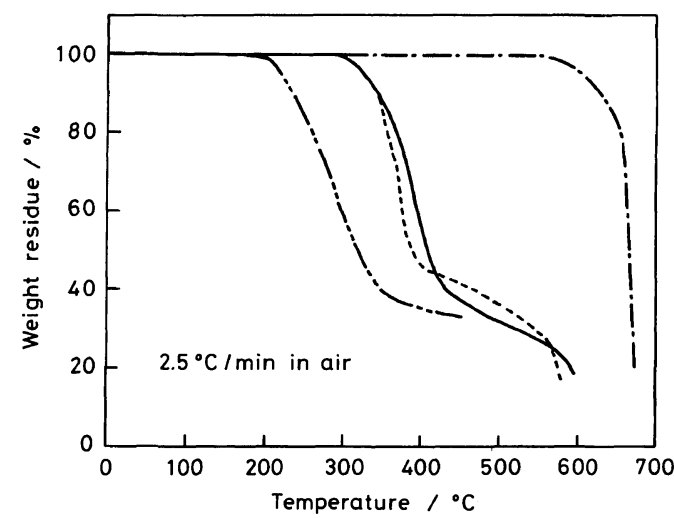

Figure 10. Thermogravimetric curves of poly-2oxazolidone-grafted carbon blacks. (-- - ), untreated Neospectra II; (-), poly-2-oxazolidone(DGBA-TDI)grafted Neospectra II (grafting ratio $=170.0 \%$ ); $(----)$, poly-2-oxazolidone (BEB-HMDI)-grafted Neospectra II (grafting ratio $=135.8 \%$ ); $(----$ ), polyester-grafted Neospectra II (grafting ratio $=145.0 \%) .2$

\section{CONCLUSIONS}

It was found that poly-2-oxazolidones were grafted onto a carbon black surface during the polyaddition of diepoxides with diisocyanates using the OLi group on carbon black as initiator. The poly-2-oxazolidone-grafted carbon black was stable in air up to $300^{\circ} \mathrm{C}$. Such a polymer-grafted carbon black is of interest in applications of carbon black-polymer composites.

\section{REFERENCES}

1. N. Tsubokawa and Y. Sone, Kobunshi Kako, 33, 129 (1984).

2. N. Tsubokawa, Nippon Gomu Kyokaishi, 58, 306 (1985).

3. K. Ohkita, N. Tsubokawa, E. Saitoh, M. Noda, and N. Takashina, Carbon, 13, 443 (1975).

4. K. Ohkita, N. Nakayama, and M. Shimomura, Carbon, 18, 277 (1980).

5. K. Ohkita, M. Shimomura, and T. Tsujita, Carbon, 16, 155 (1978); M. Shimomura, Y. Sanada, and K. Ohkita, Carbon, 19, 362 (1981).

6. N. Tsubokawa, A. Funaki, Y. Hada, and Y. Sone, $J$. Polym. Sci., Polym. Chem. Ed., 20, 3297 (1982).

7. N. Tsubokawa, A. Yamada, and Y. Sone, Polym. Bull., 10, 63 (1983). 
8. N. Tsubokawa, J. Polym. Sci., Polym. Chem. Ed., 22, 1515 (1984).

9. N. Tsubokawa, J. Appl. Polym. Sci., 30, 2041 (1985).

10. N. Tsubokawa, H. Nunokawa, and Y. Sone, J. Macromol. Sci., Chem., A23, 105 (1986).

11. N. Tsubokawa, K. Fujiki, and Y. Sone, J. Polym. Sci., Polym. Chem. Ed., in press.

12. G. P. Speranza and W. J. Peppel, J. Org. Chem., 23, 1922 (1958).

13. S. R. Sandler, F. Berg, and G. Kitazawa, J. Appl. Polym. Sci., 9, 1994 (1965); S. R. Sandler, J. Polym. Sci., $A-1,5,1481$ (1967).

14. J. E. Herweh and W. Y. Whitmore, J. Polym. Sci., $A-1,8,2756$ (1970).

15. R. R. Dileone, J. Polym. Sci., A-1, 8, 609 (1970).
16. H. Gilman and A. Haublin, J. Am. Chem. Soc., 66, 1515 (1944).

17. E. Papirer, V. T. Nguyen, and J. B. Donnet, Carbon, 16, 141 (1978).

18. K. Ohkita, N. Nakayama, and A. Funaki, Shikizai Kyokaishi, 53, 583 (1980).

19. N. Tsubokawa, Y. Nagano, and Y. Sone, Polym. Bull., 10, 404 (1983).

20. Y. Iwakura, N. Nabeya, F. Hayano, and K. Kurita, J. Polym. Sci., A-1, 5, 1865 (1967).

21. N. Kinjo, S. Numata, T. Koyama, and Y. Katsuya, Polym. J., 14, 505 (1982).

22. N. Tsubokawa, A. Yamada, and Y. Sone, Kobunshi Ronbunshu, 42, 509 (1985). 